\title{
Borehole stability in naturally fractured reservoirs during production tests
}

\author{
Zhang Fuxiang ${ }^{1}$, Zhang Shaoli ${ }^{2}$, Jiang Xuehai ${ }^{3}$, Lu Rende ${ }^{3}$ and Chen Mian ${ }^{3} *$ \\ ${ }^{1}$ Tarim Oil Field Company, PetroChina, Korla, Xinjiang 834000, China \\ ${ }^{2}$ PetroChina Company Limited, Beijing 100011, China \\ ${ }^{3}$ School of Petroleum Engineering, China University of Petroleum, Beijing 102249, China
}

\begin{abstract}
Based on the plane of weakness theory, a model for predicting borehole stability in fractured reservoirs under different stress states was estiblisted and the equations for solving borehole stability were developed. The minimum downhole pressures required to maintain borehole stability under different natural fracture occurrences were calculated by using the data from a well in the Tazhong (central Tarim) area, Tarim Basin, west China. Several conclusions were drawn for naturally fractured reservoirs with a dip angle from less than $10^{\circ}$ to greater than $30^{\circ}$. Application in three wells in the Tazhong area indicates that this model is practically useful.
\end{abstract}

Key words: Production test, fractured reservoir, borehole stability, fracture dip, azimuth of fracture

\section{Introduction}

Borehole stability problems during petroleum production cause substantial problems in all areas of the world (Aadnoy, 1988; Zheng, 1998). Studies of borehole stability mainly concentrated on the chemical performance of drilling fluids, and appropriate fluid systems were developed to ensure the stability of shales with different physical and chemical properties (Chen et al, 2003a; Deng and Meng, 2003). From shallow to deep drilling, from gentle continental sedimentary basin characterized by simple geological conditions to piedmont structural belts, active seismic zones and offshore structures with strong tectonic activity, stability problem is getting more serious (Aadnoy and Ong, 2003; Morita, 1995). Borehole instability during drilling is not only connected with the chemical properties, but also with the density of drilling fluids (Hale and Mody, 1992). When drilling a hole, the balance state of stresses near the borehole is broken down by the process of rock removal through drilling fluid circulation (van Oort et al, 1996). The support to the borehole wall is now provided by the hydrostatic pressure of the drilling fluid column. Significant progress has been made in the mechanics of borehole stability (Ottesen and Kwakwa, 1991). In the late 20th century, the coupled theory of chemistry and mechanics was the first step to solve the problem of shale stability (Mitchell and Goodman, 1987). So far, there is no report on the borehole stability in fractured reservoirs during production tests. Research on the borehole stability in fractured reservoirs has important engineering significance for production tests (Chen et al, 2003b).

\footnotetext{
* Corresponding author. mail: chenmian@vip.sina.com
} Received September 20, 2007

\section{Model of borehole stability in fractured reservoirs}

Suppose that a fracture plane in the formation is a plane of weakness, and that the strength of the formation is identical in other directions. The criterion for failure to occur along this plane can be written in the following form (Jaeger et al, 2007):

$$
\sigma_{1}-\sigma_{3}=\frac{2\left(S_{\mathrm{w}}+\mu_{\mathrm{w}} \sigma_{3}\right)}{\left(1-\mu_{\mathrm{w}} \operatorname{ctg} \beta\right) \sin 2 \beta}
$$

where $\sigma_{1}$ is the maximum principal stress; $\sigma_{3}$ is the minimum principal stress; $S_{\mathrm{w}}$ is the cohesion of the plane of weakness; $\mu_{\mathrm{w}}$ is the coefficient of internal friction of the plane of weakness; and $\beta$ is the angle between the normal to the plane of weakness and the direction of the maximum principal stress, $\sigma_{1}$.

The stress difference required to cause slippage along the plane of weakness can be found from Eq. (1). If $\beta=\phi_{\mathrm{w}}$ or $\beta=\frac{\pi}{2}$ ( $\phi_{\mathrm{w}}$ is the angle of internal friction of the plane), Eq. (1) shows $\sigma_{1}-\sigma_{3} \rightarrow 0$, i.e. slippage will not occur; if

$$
\phi_{\mathrm{w}}<\beta<\frac{\pi}{2}
$$

and the stress difference, $\sigma_{1}-\sigma_{3}$ meets Eq. (1), slippage will occur. Otherwise, rock mass failure occurs and obeys the following relationship:

$$
\sigma_{1}-\sigma_{3}=2\left(S_{0}+\mu_{0} \sigma_{3}\right)\left[\sqrt{\left(\mu_{0}^{2}+1\right)}+\mu_{0}\right]
$$

where $\mu_{0}$ is the coefficient of internal friction of rock mass; $S_{0}$ is the cohesion of rock mass.

In cylindrical coordinates, the stresses acting on the 
borehole wall of a vertical well can be expressed as follows (Jin et al, 1999a; 1999b):

$$
\left\{\begin{aligned}
\sigma_{r}= & p-\delta \varphi\left(p-p_{\mathrm{p}}\right) \\
\sigma_{\theta}= & -p+(1-2 \cos 2 \theta) \sigma_{\mathrm{H}}+(1+2 \cos 2 \theta) \sigma_{\mathrm{h}} \\
& +\delta\left[\frac{\zeta(1-2 v)}{1-v}-\varphi\right]\left(p-p_{\mathrm{p}}\right) \\
\sigma_{z}= & \sigma_{v}-\nu\left[2\left(\sigma_{\mathrm{H}}-\sigma_{\mathrm{h}}\right) \cos 2 \theta\right]+\delta\left[\frac{\zeta(1-2 v)}{1-v}-\varphi\right]\left(p-p_{\mathrm{p}}\right)
\end{aligned}\right.
$$

where $\sigma_{\mathrm{H}}$ is the maximum horizontal in-situ stress; $\sigma_{\mathrm{h}}$ is the minimum horizontal in-situ stress; $\sigma_{\mathrm{v}}$ is the vertical stress; $p_{\mathrm{p}}$ is the pore pressure; $p$ is the fluid pressure; $\varphi$ is the reservoir porosity; $\zeta$ is the coefficient of tectonic stress; $\nu$ is the Poisson ratio; $\theta$ is the angle between the maximum in-situ stress and the current orientation, anticlockwise as positive. For a permeable borehole wall, $\delta=0$; otherwise $\delta=1$.

Under different in-situ stress conditions or drilling fluid pressures, there are three cases for the principal stresses acting on the borehole wall:

$$
\begin{aligned}
& \sigma_{\theta}>\sigma_{z}>\sigma_{r} \\
& \sigma_{z}>\sigma_{\theta}>\sigma_{r} \\
& \sigma_{z}>\sigma_{\theta}>\sigma_{r}
\end{aligned}
$$

If $\sigma_{\theta}>\sigma_{z}>\sigma_{r}$, drilling fluid pressure required to maintain the stability of the plane of weakness can be written as follows:

$p_{\text {cr }}=\frac{(1-2 \cos 2 \theta) \sigma_{\mathrm{H}}+(1+2 \cos 2 \theta) \sigma_{\mathrm{h}}-m S_{\mathrm{w}}-\left[m \mu_{\mathrm{w}}(\delta \varphi-\alpha)+\delta\left(k_{1}+\varphi\right)\right] p_{\mathrm{p}}}{m \mu_{\mathrm{w}}(1-\delta \varphi)+2-\delta\left(\varphi+k_{1}\right)}$

with

$$
\begin{aligned}
& m=\frac{2}{\left(1-\mu_{\mathrm{w}} \operatorname{ctg} \beta\right) \sin 2 \beta} \\
& k_{1}=\delta\left[\frac{\zeta(1-2 v)}{1-v}-\varphi\right]
\end{aligned}
$$

where $\alpha$ is the coefficient of effective stress.

In earth coordinates $(N, E, S k y)$, there is a theoretical relationship between $T R, D I P$, and $\vec{n}$.

$$
\begin{aligned}
\vec{n} & =i \sin (D I P) \cos (T R)+j \sin (D I P) \sin (T R)+k \cos (D I P) \\
& =i a_{1}+j a_{2}+k a_{3}
\end{aligned}
$$

where $T R$ and DIP are the trend (or strike) and dip of the plane of weakness; $\vec{n}$ is the normal vector of the plane of weakness.

In principal stress coordinates, the directional vector of the major principal stress is $\vec{N}_{1}$ and can be written as follows (Chen et al, 1995):

$$
\vec{N}_{1}=i \sin \theta-j \cos \theta
$$

The directional vector of major principal stress $\left(\sigma_{\theta}\right)$ can be written as follows:

$$
\begin{aligned}
\vec{N}= & i[\cos (H A) \sin \theta+\sin (H A) \cos \theta] \\
& +j[\sin (H A) \sin \theta-\cos (H A) \cos \theta]
\end{aligned}
$$

where $H A$ is orientation of the maximum in-situ stress.

In earth coordinates, the angle between the normal to the plane of weakness and the major principal stress $\left(\sigma_{\theta}\right)$ is $\beta$, and therefore

$$
\cos \beta=\frac{\vec{n} \cdot \vec{N}}{|\vec{n}| \cdot|\vec{N}|}
$$

If $\sigma_{z}>\sigma_{\theta}>\sigma_{r}$, drilling fluid pressure required to maintain the stability of the plane of weakness can be written as follows:

$$
p_{\text {cr }}=\frac{\sigma_{v}-2 v\left(\sigma_{\mathrm{H}}-\sigma_{\mathrm{h}}\right) \cos 2 \theta-m S_{\mathrm{w}}+\left[m \mu_{\mathrm{w}}(\alpha-\delta \varphi)+\delta\left(k_{1}+\varphi\right)\right] p_{\mathrm{p}}}{m \mu_{\mathrm{w}}(1-\delta \varphi)+1-\delta\left(\varphi+k_{1}\right)}
$$

If $\sigma_{z}>\sigma_{r}>\sigma_{\theta}$, drilling fluid pressure required to maintain the stability of the plane of weakness can be written as follows:

$$
p_{\mathrm{cr}}=\frac{m_{2}-k_{2} m_{1}-m S_{\mathrm{w}}-\left(k_{1}+k_{1} k_{2}\right) p_{\mathrm{p}}}{k_{1} k_{2}-k_{1}-k_{2}}
$$

with

$$
\begin{aligned}
& m_{1}=(1-2 \cos 2 \theta) \sigma_{\mathrm{H}}+(1+2 \cos 2 \theta) \sigma_{\mathrm{h}} \\
& m_{2}=\sigma_{v}-\nu\left[2\left(\sigma_{\mathrm{H}}-\sigma_{\mathrm{h}}\right) \cos 2 \theta\right] \\
& k_{2}=1+m \mu_{\mathrm{w}}
\end{aligned}
$$

If $S_{\mathrm{w}}=0$, the stability between stratifications completely depends on frictional force. Using Eqs. (5), (10) and (11), we can easily solve the stability problem of fractured reservoirs.

\section{Influence of natural fracture occurrence on borehole stability}

The following data used are from a well in Tazhong area, Tarim Basin, west China.

The maximum in-situ stress orientation Maximum horizontal in-situ stress grads NE 75 degrees Minimum horizontal in-situ stress grads $2.46 \mathrm{MPa} / 100 \mathrm{~m}$ $1.67 \mathrm{MPa} / 100 \mathrm{~m}$ Pore pressure grads of the formation

$1.1 \mathrm{MPa} / 100 \mathrm{~m}$

Ignoring the effect of $S_{\mathrm{w}}$, and with Eqs. (5), (10) and (11), we can calculate the minimum downhole pressures required to maintain borehole stability under different natural fracture occurrences.

From Fig. 1, we can draw the following conclusions.

1) For naturally fractured reservoirs having a relatively low dip angle of less than 10 degrees, a relatively low downhole pressure is required to maintain borehole stability, and the reservoir beds are relatively stable.

2) For naturally fractured reservoirs having a low dip 




Fig. 1 Minimum downhole pressure required to maintain borehole stability

angle of 10-30 degrees, the minimum downhole pressure required to maintain borehole stability increases with increasing orientation (or azimuth) of natural fractures, and reaches a maximum value when the orientation of fractures is close to 80 degrees; after the orientation exceeds 80 degrees, the minimum downhole pressure required decreases with increasing orientation of natural fractures. This indicates that when the orientation of natural fractures is close to that of the maximum horizontal in-situ stress, borehole stability becomes worse; moreover, the greater the dip angle, the worse the borehole stability.

3) For naturally fractured reservoirs having a low dip angle of more than 30 degrees, the orientation of natural fractures is close to that of the maximum horizontal stress, the borehole is stable; moreover, the greater the dip angle, the better the borehole stability.

\section{Application}

Acid fracturing treatment was performed in a naturally fractured carbonate reservoir in the Tazhong area. The natural fracture occurrence, collapsed interval and computational data are listed in Table 1. Table 1 illustrates that the measured pressures corresponding to borehole collapse in three wells are less than the calculated minimum downhole pressures required to maintain borehole stability. This proves that the model is applicable to predicting the minimum downhole pressure required to maintain borehole stability.

Table 1 Analysis of the collapse of reservoir beds in Tazhong area (three wells)

\begin{tabular}{|c|c|c|c|c|}
\hline $\begin{array}{l}\text { Well } \\
\text { name }\end{array}$ & Natural fracture occurrence & Description of collapsed formation & $\begin{array}{l}\text { Downhole } \\
\text { pressure } \\
\mathrm{MPa}\end{array}$ & $\begin{array}{l}\text { Minimum downhole pressure } \\
\text { required to maintain borehole } \\
\text { stability, } \mathrm{MPa}\end{array}$ \\
\hline TZ-X & $\begin{array}{l}\text { Tensile cracks } \\
\text { and high-angle fractures ( } 75 \text { degrees })\end{array}$ & $\begin{array}{l}4640-4670 \mathrm{~m} . \\
\text { The depth of air lift with liquid nitrogen was } 1500 \mathrm{~m} \text {. } \\
\text { Equipment for measuring well temperature was stuck } \\
\text { at } 4647.90 \mathrm{~m} . \\
\text { Pumping depth was } 1500 \mathrm{~m} . \\
\text { Sand face depth was } 4643.46 \mathrm{~m} .\end{array}$ & 33.0 & 44.5 \\
\hline TZ-Y & $\begin{array}{l}\text { Inclined fractures were developed well, especially } \\
\text { from } 5284.02 \text { to } 5300 \mathrm{~m} \text {, fracture density was } 15 \\
\text { pieces } / \mathrm{m} \text {. }\end{array}$ & $\begin{array}{l}5225.42-5300 \mathrm{~m} \text {. } \\
\text { The density of drill-in fluid (S.G.) was } 1.04 \mathrm{~g} / \mathrm{cm}^{3} \text {. } \\
\text { Drilling returns were sharp-edged gray-white cuttings } \\
\text { and sticking occurred frequently. }\end{array}$ & 55.1 & 57.3 \\
\hline $\mathrm{TZ}-\mathrm{Z}$ & $\begin{array}{l}\text { Inclined fractures were developed well, especially } \\
\text { in the lower part of the interval that production test } \\
\text { was performed. }\end{array}$ & $\begin{array}{l}4633.40-4699.05 \mathrm{~m} \text {. } \\
\text { Sticking occurred frequently. } \\
\text { And significant sand production. }\end{array}$ & 47.0 & 49.2 \\
\hline
\end{tabular}


pressure required to maintain borehole stability.

\section{Conclusions}

Based on the plane of weakness theory, a model was developed for predicting borehole stability in fractured reservoirs under different stress states and the following conclusions were drawn:

1) For naturally fractured reservoirs with a very low dip angle of less than 10 degrees, the minimum downhole pressure required to maintain borehole stability is relatively low.

2) For naturally fractured reservoirs with a low dip angle of 10-30 degrees, the minimum downhole pressure required to maintain borehole stability increases with increasing azimuth of natural fractures, and reaches a maximum value when the azimuth of fracture is close to 80 degrees; after the azimuth exceeds 80 degrees, the pressure required to maintain borehole stability decreases with the increasing azimuth of natural fractures. This indicates that when the azimuth of natural fractures is close to the orientation of maximum horizontal in-situ stress, borehole stability becomes worse; moreover, the greater the dip angle, the worse the borehole stability.

3) For naturally fractured reservoirs with a dip angle of greater than 30 degrees, when the azimuth of natural fractures is close to the orientation of maximum horizontal stress, borehole stability becomes better; moreover, the greater the dip angle, the better the borehole stability.

\section{References}

Aadnoy B S. Modeling of the stability of highly inclined boreholes in anisotropic rock formations. SPE Drilling Engineering. 1988. 3(3): 259-268 (SPE number 16526)

Aadnoy B S and Ong S H. Introduction to special issue on borehole stability. Journal of Petroleum Science and Engineering. 2003. 38(3): 79-82
Chen G Z, Chenevert M E, Sharma M M, et al. A study of wellbore stability in shales including poroelastic, chemical and thermal effects. Journal of Petroleum Science and Engineering. 2003a. 38(3): 167-176

Chen M, Chen Z X and Huang R Z. Hydration stress on wellbore stability. Rock Mechanics, Proceedings of the 35th U.S. Symposium. 1995. 885-888

Chen X, Tan C P and Detournay C. A study on wellbore stability in fractured rock masses with impact of mud infiltration. Journal of Petroleum Science and Engineering. 2003b. 38(3): 145-154

Deng $\mathrm{H}$ and Meng Y F. A discussion on shale stability coupling mechanics and chemistry. Petroleum Exploration and Development. 2003. 30(1): 109-111 (in Chinese)

Hale A H and Mody F K. Experimental investigation of the influence of chemical potential on wellbore stability. IADC/SPE Drilling Conference held in New Orleans, Louisiana, 18-21 February 1992 (SPE number 23885)

Jaeger J C, Cook N G W and Zimmerman R W. Fundamentals of Rock Mechanics (4th edition). London: Blackwell Publishing. 2007

Jin Y, Chen M, Chen Z X, et al. Wellbore mechanics stability problem of vertical well in weakly consolidated reservoirs. Drilling \& Production Technology. 1999a. 22(3): 13-14 (in Chinese)

Jin Y, Chen M, Liu G H, et al. Wellbore mechanics stability problem of directional well in weakly consolidated reservoirs. Drilling \& Production Technology. 1999b. 23(4): 33-35 (in Chinese)

Mitchell R F and Goodman M A. Borehole stresses plasticity and the drilled hole effect. SPE/IADC Drilling Conference held in New Orleans, Louisiana, 15-18 March 1987 (SPE number 16053)

Morita N. Uncertainty analysis of borehole stability problems. SPE Annual Technical Conference \& Exhibition held in Dallas, USA, 22-25 October 1995 (SPE number 30502)

Ottesen S and Kwakwa K A. A multidisciplinary approach to in-situ stress determination and its application to wellbore stability analysis. SPE/IADC Drilling Conference held in Amsterdam, Netherlands, 11-14 March 1991 (SPE number 21915)

van Oor E, Hale A H, Mody F K, et al. Transport in shales and the design of improved water-based shale drilling fluids. SPE Drilling \& Completion. 1996. 11(3): 137-146 (SPE number 28309)

Zheng Z. Integrated borehole stability analysis: Against tradition. SPE/ISRM Rock Mechanics in Petroleum Engineering held in Trondheim, Norway, 8-10 July 1998 (SPE number 47282)

(Edited by Sun Yanhua) 